\title{
Chromium Trioxide
}

National Cancer Institute

\section{Source}

National Cancer Institute. Chromium Trioxide. NCI Thesaurus. Code C45886.

A dark red to brown colored, crystalline, inorganic compound that emits toxic chromium fumes upon heating. Chromium trioxide is highly corrosive and is a strong oxidizing agent. This substance is mainly used in the production of wood preservatives and organic chemicals, but is also used in metal finishing and chrome plating and as a corrosion inhibitor. Chromium trioxide primarily affects the nose, throat and lungs causing ulcerations, shortness of breath, bronchitis, pneumonia and asthma-like allergy but can also affect the gastrointestinal tract, liver, kidneys and immune system. This substance is a known human carcinogen and is associated with an increased risk of developing lung cancer and cancer of the sinonasal cavity. (NCI05) 